\title{
Engineered Weld Design: Are Composite Welds Likely In The Future?
}

\author{
D.L. Olson ${ }^{1, a}$, Y.D. Park ${ }^{2, b}$, S. Liu, ${ }^{1, c}$, J.E. Jackson ${ }^{1, d}$, and A.N. Lasseigne- \\ Jackson $^{1, e}$, E. Metzbower ${ }^{3, f}$ \\ ${ }^{1}$ Colorado School of Mines, 1500 Illinois St., Golden, CO 80401 USA \\ ${ }^{2}$ Dong-Eui University, Busan, Korea \\ ${ }^{3}$ EAMWeld LLC, 8716 Bluedale Street Alexandria, VA \\ edolson@mines.edu, 'bypark@deu.ac.kr, 'sliu@mines.edu, djoshjack@mines.edu, \\ ealasseig@mines.edu, fed@eamweld.com
}

Keywords: Composite Welds; Hybrid Design; Consumable, Parameter, and Process Selection

\begin{abstract}
Utilizing alternating welding process parameters, deposition practices, and welding consumables, particularly during multiple pass welding, it is possible to improve a variety of weld metal properties. There are available a number of phenomena occurring during welding that allow weld metal designers the ability to generate macro- and micro-structural features amenable to implementation of composite theory. These phenomena include solidification microsegregation during dendrite growth, gas-metal reactions between the selected alternating shielding gas composition and weld pool, and solidification microstructural orientation during welding. Additional methods of producing composite welds including specially designed weld compositions, weld metal solidification modification by arc pulsing, and dual wire deposition may be utilized to achieve single pass and multipass composite weld metal deposition. Composite welds are a potential method to solve challenging demands such as high-toughness at low temperature, creep strength at high temperature, and customized design for corrosion, wear, or cracking resistance.
\end{abstract}

\section{Introduction}

Advances in process control, consumables, and deposition practice methods have made possible engineered weld design of composite-like welds with advanced properties, such as high strength and high toughness. These methods rely on advanced property prediction techniques, including compositional property prediction, influence of weld oxide and interstitial content, solidification effect on inclusion formation, among other techniques. Advances in consumable creation and deposition practices, as well as advanced power supply control capabilities, further extend potential methods for weld property control needed to create successful composite welds. Composite welds make ordered use of existing composition, microstructure, and property gradients that welds already exhibit, as noted in five types of variation in the multipass weld macrostructure in Figure 1[1], where the dash-and-dots arrow is bead-to-bead and the dotted arrow is variation in the bead. Composite will welds require intelligently engineered variation of properties, materials, and weld bead architectures.

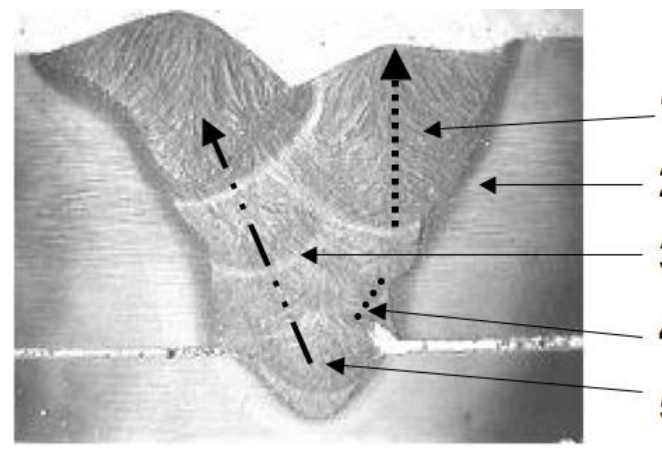

1. Macroscopic Variation

2. Base Metal Heat Affected Zone

3. Weld Metal Heat Affected Zone

4. Interdendritic Segregation

5. Bead-to-bead variations

Figure 1. Five regions of variation are illustrated in a typical multipass weld [1]. 
Regions of tempered martensite, ferrite, and untempered martensite may exist in a multipass highstrength steel weld due to normal welding practice. This non-uniform weld structure also occurs at the microstructural level. If it can be successfully controlled, enhanced weld properties can be achieved by use of composite theory. Dendritic solidification tends to segregate some elements to interdendritic regions [2], causing a coring of weld elemental compositions across each grain [3], corresponds Figure 2(A). This intragranular coring phenomena causes striations of martensite streaks across zones of bainitic product in each grain of AISI 4340 steel welds, as shown in Figure 2(B). Oscillation of the coring across the grain, as shown in Figure 2(C), will oscillate the bainitic nose, which explains the weld metal microstructural evolution [4].

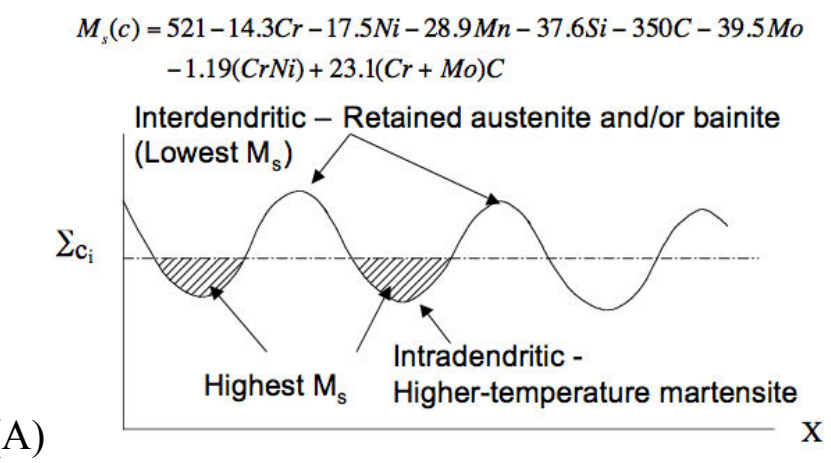

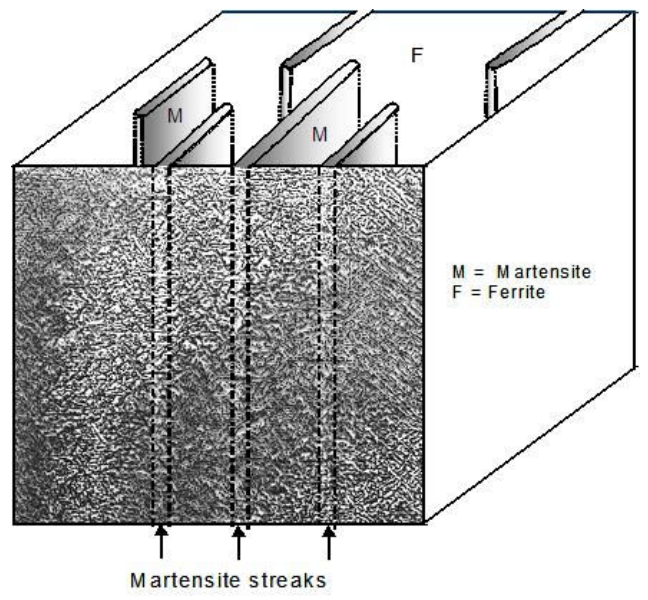

(B)

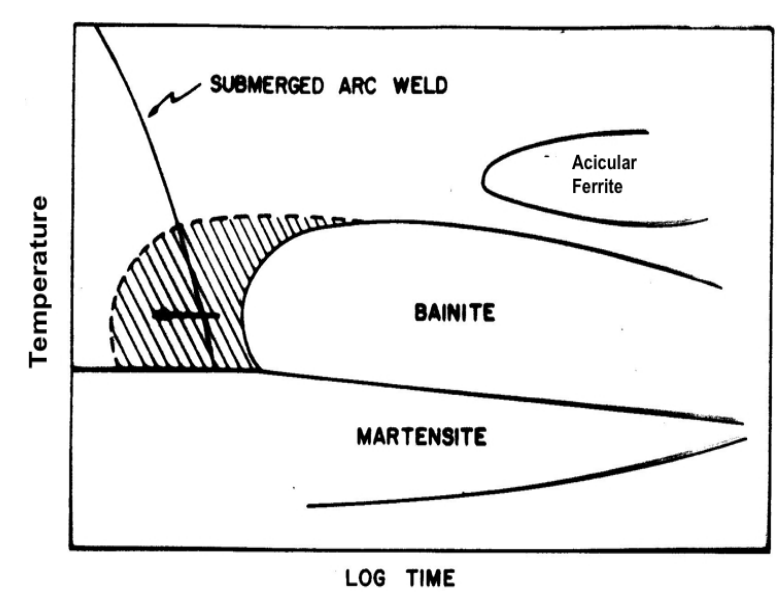

(C)

Figure 2. (A) Dendritic coring structure [3], (B) martensitic streaks formed in a ductile ferrite matrix, and (C) bainite nose shifting [4].

Applications Application needs like high-strength with high-toughness, enhanced corrosion resistance, high creep strength, and other specialized property designs are often not practical or economical to achieve using conventional welding practices. A number of phenomena exist in welding which lend themselves to application for creating composite welds. Advances in modeling and simulation of the phenomena driving heat and mass transfer in the weld pool have made more accurate control of welding phenomena possible.

Length-Varying Flux- and Metal-Cored Wires Cored consumables with length-varying compositions have been used to create multiple-composition welds with alternating properties for special applications, and offers potential to reduce or eliminate post-weld heat treatment of fluxcored welds. Alternating composite-like structures can be created by use of cored wires with regular variation of composition along the length of the wire. Alternating steel with stainless steel can take advantage of the coefficient of thermal expansion mismatch [5] between the two materials, as illustrated in Figure 3(A), to place alternating regions in compression and tension in a manner that can mitigate crack propagation. By varying the amount and distribution of depositions with different thermal expansions using techniques such as length-varying cored wire, it should be 
possible to control thermally processed residual stresses and distortion according to composite modeling and proper thermal processing control. With proper process control it is possible to achieve a pattern of ductile and strengthened phase that, when loaded, will yield in the ductile phase enough to load the stronger phase, achieving a potential combination of both higher weld strength and toughness. Length-varying cored wires can include additions of wear-resistant, stainless, hydrogen trapping, exothermic, and numerous other alloys additions to achieve desired properties [6]. Alternating or pulsing shielding gases, such as pure argon with small additions of methane or interstitial gases, may also be used to create composite welds. The metal particulate-filled cored wire will only produce precipitates during the time when the reaction gas is shielding the weld [7], as shown in Figure 3(B).

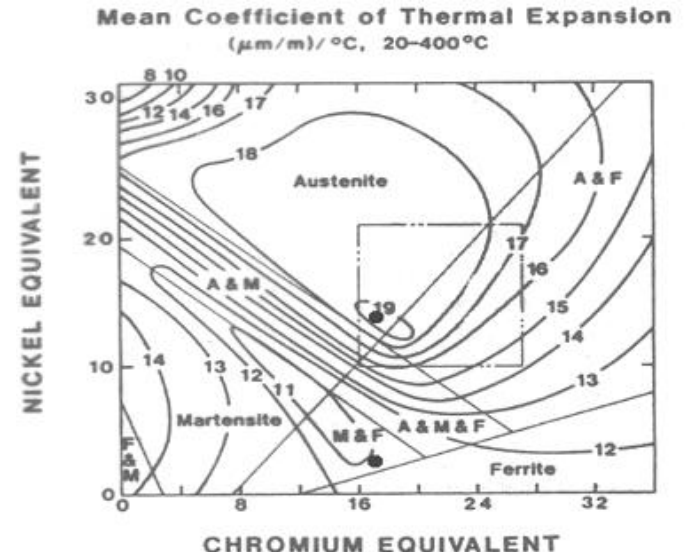

(A)

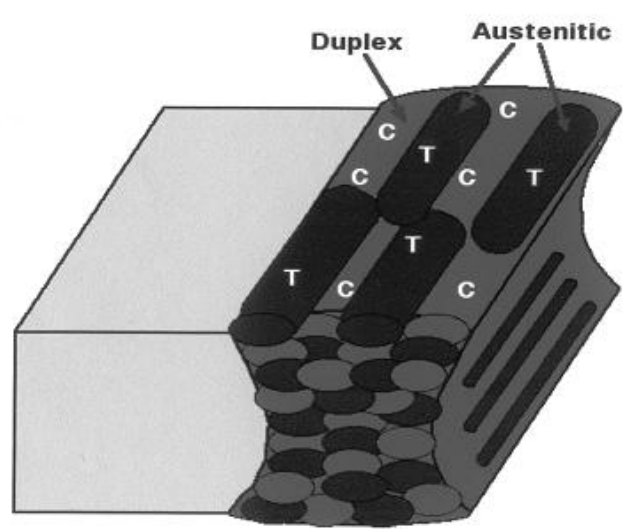

(B)

Figure 3. Length-varying metal-cored wired with (A) stainless steel alloy inserted at regular length intervals with ductile steel for increased wear resistance with ductility [5] and (B) shielding gas variation to create alternating duplex and austenitic weld metal regions [7].

Pulsed Heat Input In Figure 4(A) below, the top weld pattern consisted of approximately fifty percent as-solidified weld metal while the bottom weld consisted of very little as-solidified weld metal. These weld patterns were produced by varying welding parameters and weld bead sequencing [8], and similar techniques could be successfully utilized to create composite welds with a variety of materials. Heat input correlates linearly to carbon equivalent and hardness, as in Figure 4(B), where the dotted lines represent pulsed heat input. Exothermic welding additions (white gray) are an alternative for producing composite-like single and multipass welds and could be made as length-varying flux-cored wire additions to steel (tan) welding wires, as in Figure 4(C).

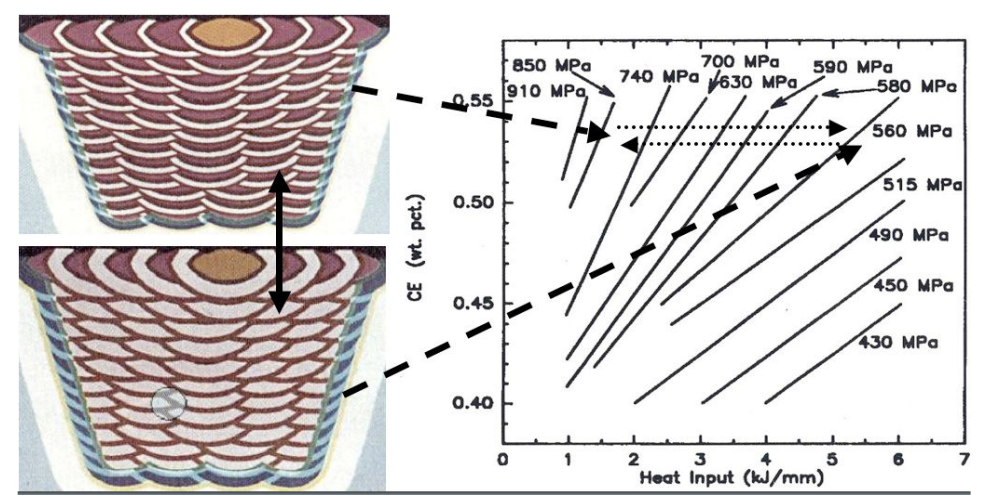

(A)
(B)

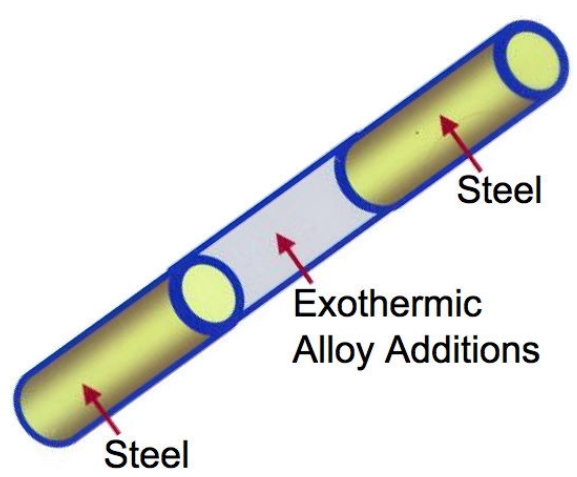

(C)

Figure 4. Variation in heat input leading to (A) different weld microstructures [8] is illustrated on (B) an equal property diagram [9] where pulsing may be achieved by periodic use of (C) exothermic alloy additions (light gray) in length-varying steel (light brown) cored wires. 
Process Control Pulsing and advances in welding deposition control, such as robotic, laser, and dual-wire deposition make composite welding more feasible by allowing control of deposited layers with high accuracy to create multipass welds in which composite-like regions are alternated to achieve specific engineered weld metal architecture. There are also advantages from using macroscopic phenomena such as alternating the weld travel direction or deposition to break the texture and any segregation behavior between weld passes. Reversing weld travel direction between passes in multi-pass welding will achieve grain refinement and reduce anisotropic tendencies in welds [6]. Modern processing methods such as multiple robotic welding torches, hybrid welding, and laser-assisted GMAW will make consistent composite welding much more achievable. Pulsing and directionu reversal help to change the epitaxial growth angle and force renucleation rather than precipitation. Pulsing gives fine microstructure with different crystal directions that increases toughness. Lines represent dendrite formation with columnar grains.

(A)

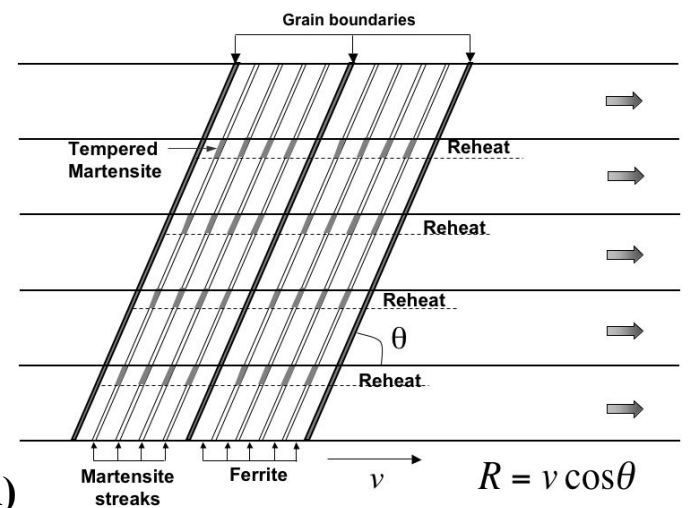

(B)

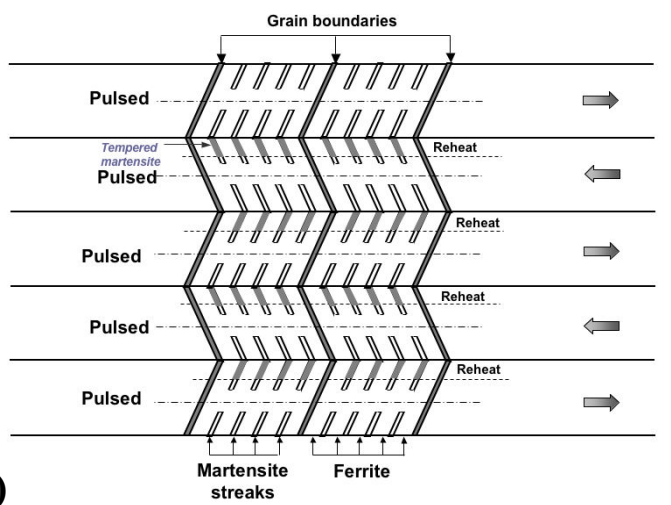

Figure 6. Multipass welding operation is shown in (A) with same direction and speed of weld travel and (B) with pulsing and direction-reversal are used to form a composite-like structure with more tortuous crack paths achieving greater toughness with similar or higher strength [6].

\section{Summary}

Composite welding requires engineered design and mechanics. Specialized consumables, coordinated welding processes and parameters, metallurgical understanding of weld metal microstructure evolution, and automation and/or advanced robotics will be needed to consistently make composite welds. Composite welds offer amplified properties like strength and toughness, solutions for specialized applications, and high integrity.

\section{References}

[1] D.W. Moon, S.G. Lambrakos, R.J. Wong, and E.A. Metzbower, Sci. Tech. of Welding \& Joining, Vol. 8, Number 2, (2003), pp. 95-101.

[2] R. H. Frost, S. Liu, and D. L. Olson, Proc. 3rd Intn. Conference on Trends in Welding Research, June 15, 1992, Gatlinburg, TN, pp. 205-209, ASM, Materials Park, OH (1993).

[3] J. A. Self, D. K. Matlock and D. L. Olson, "An Evaluation of Austenitic Fe-Mn-Ni Weld Metal for Dissimilar Metal Welding", Welding Journal 63, 282s-288s (1984).

[4] P.A. Burke, J. E. Indacochea, and D. L. Olson, "The Effects of Welding Flux Additions on 4340 Steel Weld Metal Composition", Welding Journal 69 (3), 115s-122s (1990).

[5] J. W. Elmer, D. L. Olson, and D. K. Matlock, "Thermal Expansion Characteristics of Austenitic Stainless Steel Filler Metals", Welding Journal 61 (9), 293S-301S (1982).

[6] D. L. Olson, E. Metzbower, S. Liu and Y. D. Park, Proc. on Intl. Conf., Paton Electric Welding Institute, Kiev, Ukraine, Nov. 2003, The Paton Welding Journal, 10-11 pp. 31-37 (2003).

[7] D.W. Oh, Private communication with authors, 2003.

[8] L.-E. Svensson: Control of Microstructures and Properties in Steel, CRC Press, U.S.A. (1994.)

[9] A.O. Kluken, S. Ibarra, S. Liu, and D.L. Olson, "Use of Predictive Equations for Arctic Steel Heat Affected Zone Properties", in Conf. Proc. on 'Offshore Mechanics and Arctic Engineering - Materials Engineering', ASME, Vol. A, pp. 1-7, Calgary, Canada, June 1992. 